Original Article

\title{
The effects of abdominal interferential current therapy on waist circumference and visceral fat distance in obese women
}

\author{
Young-Han Park, PhD ${ }^{1)}$, Jung-Ho LeE, $\mathrm{PhD}^{2)^{*}}$ \\ 1) Department of Physical Therapy, Korea National University of Transportation, Republic of Korea \\ 2) Department of Physical Therapy, Kyungdong University: Bongpo-ri, Toseong-myeon, Goseong-gun, \\ Gangwon-do, Republic of Korea
}

\begin{abstract}
Purpose] The purpose of this study was to investigate the effects of interferential current therapy on the waist circumference and visceral fat length in obese women. [Subjects and Methods] In this study, we selected 30 patients whose body mass index was over $25 \mathrm{~kg} / \mathrm{m}^{2}$. The subjects were randomly assigned to receive interferential current therapy three times a week for four weeks $(\mathrm{n}=15)$ and transcutaneous electrical nerve stimulation three times a week for four weeks ( $\mathrm{n}=15$ ). Waist circumference was measured in $\mathrm{cm}$ using a tape measure with the participant in an upright posture, and the length of visceral fat was measured using a high-resolution, B-mode ultrasound machine. [Results] There was a statistically significant difference between the group of waist circumference and visceral fat length. The change of waist circumference and visceral fat length was larger the experimental group than the control group. [Conclusion] These results can be used as a basis for reducing the risk factors that increase mortality due to diseases and can prevent cardiovascular and other adult diseases caused by obesity. Key words: Obesity, ICT, Visceral fat length
\end{abstract}

(This article was submitted May 22, 2017, and was accepted Jun. 20, 2017)

\section{INTRODUCTION}

Obesity, which is increasing day by day in modern people, causes psychological and social depression and increases the risk of adult diseases such as hypertension, arteriosclerosis, diabetes, and hyperlipidemia ${ }^{1)}$. However, it has been reported that the distribution of fat tissue in the body is more important than the degree of obesity in many metabolic and ischemic cardiovascular diseases. Obesity is closely linked to cardiovascular diseases such as cardiovascular disease, type 2 diabetes, high blood pressure, and it is reported that a high body mass index (BMI) increases hypertension, type II diabetes, and coronary artery disease ${ }^{2}$. Abdominal obesity, rather than systemic or metabolic obesity, is a risk factor for cardiovascular disease and should be reduced with diet, exercise, and medication. Recent studies have shown that excess body fat is more closely related than overweight to obesity-related metabolic disease complications, and abdominal fat, especially visceral fat, has been acknowledged to be metabolically more significant than body fat ${ }^{3}$.

Although there are some differences depending on its cause, methods for managing obesity can roughly be classified as dietary therapy, exercise therapy, drug therapy, and electric stimulation therapy ${ }^{4}$. There are many differences in the most effective ways to reduce obesity, and there are many ways to manage obesity. With regard to electric stimulation therapy, interferential current therapy (ICT) is used to effectively stimulate deep tissues while minimizing skin resistance ${ }^{5)}$. Lowfrequency therapy has a disadvantage in that the stimulation time is relatively long due to the use of a frequency of less than $1,000 \mathrm{~Hz}$, which is not effective in reducing skin resistance and excessively stimulates the sensory nerve, thereby causing pain $^{6}$. On the other hand, ICT uses a base medium frequency that is between $3,000 \mathrm{~Hz}$ and $6,000 \mathrm{~Hz}$. This type of wave

*Corresponding author. Jung-Ho Lee (E-mail: 1jhcivapt@naver.com)

(C2017 The Society of Physical Therapy Science. Published by IPEC Inc.

(c) (1) $\odot$ This is an open-access article distributed under the terms of the Creative Commons Attribution Non-Commercial No Derivatives

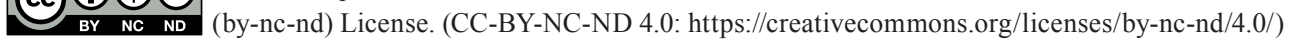


therapy generally combines two similar currents, such as $4,000 \mathrm{~Hz}$ and $4,100 \mathrm{~Hz}$, to induce an interfering current in the range of $1 \mathrm{~Hz}-100 \mathrm{~Hz}$ at the desired treatment site. There are several factors that affect the ICT effect: main frequency, beat frequency, beat duration, electrode type, and position ${ }^{7}$.

ICT has been used in clinical practice to reduce pain and is particularly effective in the treatment of back pain, skeletal pain, temporomandibular joint pain, and fracture. This type of therapy has been shown to increase blood circulation, subcutaneous tissue metabolism activation, and lymphatic and venous return, and is effective in relaxing muscular tension/ muscle stimulation and in the treatment of psoriasis, edema reduction, and improved lipolytic effect in the frequency region. However, the exact mechanism has not yet been clarified ${ }^{8,9)}$.

Currently, the indiscriminate use of some devices or drugs can partially remove or reduce fat, but the results of these treatments have been rarely studied. There have been many studies on the reduction of subcutaneous fat mass, but the research on the reduction of visceral fat volume is insufficient. The purpose of this study was to investigate the effects of ICT on the waist circumference and visceral fat length in obese women.

\section{SUBJECTS AND METHODS}

This study was conducted with obese women who were hospitalized and were not taking medication for diabetes, endocrine disease, renal dysfunction, oral contraception, hypertension, or hyperlipidemia. The BMI of selected study participants was measured via the bioimpedance analysis method, using direct measurement with eight electrodes and an InBody 3.0 machine (InBody Biospace, Seoul, Korea). The patients, whose feet were bare and who were dressed in the lightest possible attire, were placed on the machine; both hands and both thumbs were then placed on the electrode.

In this study, we selected 30 patients whose BMI was over $25 \mathrm{~kg} / \mathrm{m}^{2}$ and whose Beck Depression Inventory score was over 16. The subjects were randomly assigned to receive interferential current therapy three times a week for four weeks $(n=15)$ and transcutaneous electrical nerve stimulation three times a week for four weeks $(n=15)$. All the subjects understood the purpose of this study. And this study's subjects provided their written informed consent prior to their participation according as the ethical standards of the Declaration of Helsinki.

An interfering current therapy device (Nemectron $\mathrm{GmbH}$, Germany) was used as follows: cuffs were wrapped around the participant's abdomen during 45-minute sessions, three times a week, (a total of 12 times for 4 weeks). The program configuration was applied for 5 minutes at the interferential wave frequency of $3 \mathrm{~Hz}$, then 30 minutes at $50 \mathrm{~Hz}$, and 10 minutes at $10 \mathrm{~Hz}$. TENS was applied to the abdomen using a low-frequency electrical stimulator (STT-100, Stratek, Korea). The stimulation parameters of the triangle wave were applied at $100 \mathrm{~Hz}$ three times a week, once for 45 minutes (for 4 weeks). All treatment interventions were performed within the tolerance level of the patient, and the treatment was performed by a physical therapist who had at least 10 years of clinical experience.

Waist circumference was measured in $\mathrm{cm}$ using a tape measure with the participant in an upright posture, and the length of visceral fat was measured using a high-resolution, B-mode ultrasound machine (HDI 5000, ATL, Phillips). The visceral fat length was measured at $1 \mathrm{~cm}$ above the navel with a $3.5 \mathrm{MHz}$ probe with the subject lying in a comfortable position. The visceral fat length was defined as the length from the inner surface of the abdominal wall to the anterior wall of the aorta. Pre-tests were completed before the experiment, and post-tests were performed 4 weeks after the experiment.

The values of result were stated in mean \pm SD. PASW 18.0 for window was used for statistical analysis in this study. To analyze the difference between before and after interventions, paired t-test was used. Furthermore, independent $t$-test was used again to compare the differences between two groups. The level of significance was $\alpha=0.05$.

\section{RESULTS}

The length of the waist circumference was statistically significant in all groups in the pre- and post-evaluations $(\mathrm{p}<0.05)$ (Table 1). There was also a statistically significant difference between the group of waist circumference and the change of waist circumference was larger the experimental group than the control group $(p<0.05)$. The length of the visceral fat was statistically significant in the pre- and post-evaluations $(p<0.05)$ (Table 2$)$. There was a statistically significant difference between the group of visceral fat length, and the change of visceral fat length was larger the experimental group than the control group $(\mathrm{p}<0.05)$.

Table 1. Comparison of waist size between groups

\begin{tabular}{lcc}
\hline & $\begin{array}{c}\text { Experimental group } \\
(\mathrm{n}=15)\end{array}$ & $\begin{array}{c}\text { Control group } \\
(\mathrm{n}=15)\end{array}$ \\
\hline Pre-test & $86.63 \pm 10.96$ & $88.75 \pm 11.35$ \\
Post-test $^{\#}$ & $73.85 \pm 8.16^{*}$ & $79.12 \pm 8.53^{*}$ \\
\hline$* \mathrm{p}<0.05$, unit: $\mathrm{cm},{ }^{*}$ within group, ${ }^{*}$ between group
\end{tabular}

Table 2. Comparison of visceral fat distance between groups

\begin{tabular}{lcc}
\hline & $\begin{array}{c}\text { Experimental group } \\
(\mathrm{n}=15)\end{array}$ & $\begin{array}{c}\text { Control group } \\
(\mathrm{n}=15)\end{array}$ \\
\hline Pre-test & $5.52 \pm 1.37$ & $5.24 \pm 1.95$ \\
Post-test $^{\#}$ & $3.86 \pm 0.85^{*}$ & $4.12 \pm 0.78^{*}$ \\
\hline${ }^{*} \mathrm{p}<0.05$, unit: $\mathrm{cm},{ }^{*}$ within group, ${ }^{*}$ between group
\end{tabular}




\section{DISCUSSION}

Efforts to eliminate obesity in modern society are underway; however, more efficient methods of obesity management are required ${ }^{10)}$. The purpose of this study was to investigate the effects of interfering current therapy on abdominal visceral fat length and waist circumference.

Obesity, a nutritional disorder in which there is an excess accumulation of fat tissue in the body, is caused by an increase in fat cells and abnormal differentiation due to energy imbalances ${ }^{11)}$. Adipocytes that cause obesity function only as an energy reservoir, and it has recently been learned that various protein hormones are secreted from endocrine organs and play an important role in regulating the body's energy metabolism, including that of glucose and fat ${ }^{12}$. Thus, although adipose tissue is an essential factor in the physiological process of the human body, an excessive accumulation of fat is a major cause of cardiovascular and other diseases in adults. At present, Korea is experiencing the same situation as Western countries: Social health costs are increasing, and the state of public health is decreasing, due to an upsurge in various chronic diseases caused by obesity, a problem that is worsening ${ }^{13)}$.

The distribution of central body fat, due to an increase in abdominal obesity, has been shown to be a potential factor in high morbidity and mortality rates. The lack of physical activity and excessive energy intake is increasing the risk of developing obesity due to diabetes, coronary artery disease (CAD), hypertension, and hyperlipidemia. In general, the risk of complications from obesity increases with the obesity level ${ }^{14}$. However, while the amount of excess fat should be considered, fat distribution in the body is also important: Fats in the abdominal viscera are more significant health threats than fat in other areas. Therefore, the reduction of abdominal fat due to weight loss may be a way to reduce the risk of obesity ${ }^{15)}$.

It is now well known that increased abdominal fat tissue is a more important determinant of metabolic and cardiovascular disease than diabetes. Since Koreans are smaller than European people, the standard of abdominal obesity is more than $94 \mathrm{~cm}$ for men and $80 \mathrm{~cm}$ for women. However, there have been an insufficient number of valid studies to determine whether abdominal obesity is appropriate for the waist circumference ${ }^{16}$.

Currently, clinical treatment for obesity includes drug therapy, lipolysis, IMS, electrotherapy (mid-frequency and lowfrequency), and cognitive behavioral therapy. Physical therapy for obesity management has long been applied via water therapy, electrotherapy, and stimulation therapy. However, as the application of exercise programs due to busy daily lives becomes difficult, obesity management using electrotherapy has begun to attract attention ${ }^{17}$. ICT for obesity management is a non-invasive method, and the higher the frequency, the less capacitance resistance (i.e., the current can easily pass through the skin). Based on the above description, interferential wave therapy can stimulate internal tissues effectively, with less irritation to the skin compared to low-frequency currents ${ }^{18)}$.

The limitations of this study consisted of fewer subjects and shorter treatment intervention periods (4 weeks). It would be difficult to generalize the results of the study because they represent evaluations of waist circumference and length of abdominal visceral fat only. Because the duration of the treatment intervention was only 4 weeks, we were unable to determine the long-term effects of therapeutic intervention.

The results of this study showed that interventional current therapy applied to the abdomen could reduce the waist circumference and visceral fat length. These results can be used as a basis for reducing the risk factors that increase mortality due to diseases and can prevent cardiovascular and other adult diseases caused by obesity. The results of this study can be used as basic data with which to develop treatment equipment that can reduce abdominal visceral fat more precisely and comprehensively.

\section{ACKNOWLEDGEMENT}

This study was supported by Korea National University of Transportation 2017.

\section{REFERENCES}

1) Rahmouni K: Obesity-associated hypertension: recent progress in deciphering the pathogenesis. Hypertension, 2014, 64: 215-221. [Medline] [CrossRef]

2) Fitzgibbons TP, Czech MP: Epicardial and perivascular adipose tissues and their influence on cardiovascular disease: basic mechanisms and clinical associations. J Am Heart Assoc, 2014, 3: e000582. [Medline] [CrossRef]

3) Chang CS, Lu YJ, Chang HH, et al.: Role of adiponectin gene variants, adipokines and hydrometry-based percent body fat in metabolically healthy and abnormal obesity. Obes Res Clin Pract, 2016, S1871-403X(16)30031-X. [Medline]

4) Oh S, Tanaka K, Warabi E, et al.: Exercise reduces inflammation and oxidative stress in obesity-related liver diseases. Med Sci Sports Exerc, 2013, 45: 2214-2222. [Medline] [CrossRef]

5) Pai SI, Lin YY, Macaes B, et al.: Prospects of RNA interference therapy for cancer. Gene Ther, 2006, 13: 464-477. [Medline] [CrossRef]

6) Lee LK, Kim JH, Kim MY, et al.: A pilot study on pain and the upregulation of myoglobin through low-frequency and high-amplitude electrical stimulationinduced muscle contraction. J Phys Ther Sci, 2014, 26: 985-988. [Medline] [CrossRef] 
7) Li J, Ruan J, Du Z, et al.: Analysis of interference current for high-voltage arresters based on resistance-capacitance network. IEEE Trans Magn, 2015, 51: 1-4.

8) Albornoz-Cabello M, Maya-Martín J, Domínguez-Maldonado G, et al.: Effect of interferential current therapy on pain perception and disability level in subjects with chronic low back pain: a randomized controlled trial. Clin Rehabil, 2017, 31: 242-249. [Medline] [CrossRef]

9) Youn JI, Lee HS, Lee S: Determination of effective treatment duration of interferential current therapy using electromyography. J Phys Ther Sci, 2016, 28: 2400-2403. [Medline] [CrossRef]

10) Phillips K, Wood F, Kinnersley P: Tackling obesity: the challenge of obesity management for practice nurses in primary care. Fam Pract, 2014, 31: 51-59. [Medline] [CrossRef]

11) Cornier MA, McFadden KL, Thomas EA, et al.: Propensity to obesity impacts the neuronal response to energy imbalance. Front Behav Neurosci, 2015, 9: 52. [Medline] [CrossRef]

12) Claussnitzer M, Dankel SN, Kim KH, et al.: FTO obesity variant circuitry and adipocyte browning in humans. N Engl J Med, 2015, 373: 895-907. [Medline] [CrossRef]

13) Frieden TR: SHATTUCK LECTURE: the future of public health. N Engl J Med, 2015, 373: 1748-1754. [Medline] [CrossRef]

14) Robroek SJ, Reeuwijk KG, Hillier FC, et al.: The contribution of overweight, obesity, and lack of physical activity to exit from paid employment: a metaanalysis. Scand J Work Environ Health, 2013, 39: 233-240. [Medline] [CrossRef]

15) Hwang YC, Hayashi T, Fujimoto WY, et al.: Visceral abdominal fat accumulation predicts the conversion of metabolically healthy obese subjects to an unhealthy phenotype. Int J Obes, 2015, 39: 1365-1370. [Medline] [CrossRef]

16) Kim CS, Ko SH, Kwon HS, et al. Taskforce Team of Diabetes Fact Sheet of the Korean Diabetes Association: Prevalence, awareness, and management of obesity in Korea: data from the Korea national health and nutrition examination survey (1998-2011). Diabetes Metab J, 2014, 38: 35-43. [Medline] [CrossRef]

17) Richmond SA, Fukuchi RK, Ezzat A, et al.: Are joint injury, sport activity, physical activity, obesity, or occupational activities predictors for osteoarthritis? A systematic review. J Orthop Sports Phys Ther, 2013, 43: 515-B19. [Medline] [CrossRef]

18) Suh HR, Han HC, Cho HY: Immediate therapeutic effect of interferential current therapy on spasticity, balance, and gait function in chronic stroke patients: a randomized control trial. Clin Rehabil, 2014, 28: 885-891. [Medline] [CrossRef] 